\title{
Exploring Socio-Economic Impact of Dengue Fever in Dhaka City: A Statistical Modeling Approach
}

\author{
Mohammad Ahsan Uddin* \\ Department of Statistics, University of Dhaka, Dhaka, Bangladesh. \\ *Correspondence: munna_stat@yahoo.com (Mohammad Ahsan Uddin, Associate Professor, Department of Statistics, \\ University of Dhaka, Dhaka, Bangladesh).
}

\begin{abstract}
There was a sudden increase in dengue affected people in Dhaka city during 2018 and 2019, considering the seriousness of the disease, this study attempted to investigate the socio-economic impact of dengue fever instead of its biological significance. The study considered a primary dataset of 235 affected and 235 unaffected participants from Dhaka city. The impact of dengue infection on the monthly expenditure of the patient was determined by the multiple linear regression models. The impact of Dengue on the human productivity of the respondents was assessed by another multiple linear regression model; the dependent variable absence (number of days absent from work) was applied as a proxy for measuring the productivity of the patient. Moreover, an important objective was to find out potential determinants of dengue in Dhaka city. Binary logistic regression applied for detecting the factors which were responsible for occurring dengue disease. The study found no significant association of family cost with dengue incidence but the loss of productivity turned out as statistically significant. People who lived alone were identified to experience the disease more, which might occur due to their insincerity about this disease. So, living alone persons need to increase their consciousness considering the seriousness of this disease. It was highly recommended by respondents to use mosquito repellent and net during sleeping, changing the water regularly from plant container, providing regular mosquito spray, and developing a drainage system in Dhaka city.
\end{abstract}

Keywords: Socio-economic impact, Productivity, Potential determinants, Risk factors, and Multiple responses.

\section{INTRODUCTION:}

Contagious diseases have emerged as a main indicatory factors of poverty and poor health status in developing and under-developed countries (Kumar et al., 2007). In 2018 \& 2019, dengue viral epidemic in Bangladesh affected the ability and strength of working people to carry on with day to day activities. In many countries, dengue is a public health problems (Okanurak et al., 1997). The term "Dengue" was first originated in Zanzibar naming "Denga" during 1870 epidemic (Mahmood \& Mahmood, 2011). The dengue virus usually spreads by day biting female Aedes mosquitoes, primarily Aedes aegypti and Aedes albopictus (Sharmin et al., 2015). Climate change will increase severity of dengue in the future (Naish et al., 2014).

Bangladesh has made a noticeable progress in child mortality and maternity sector by developing primary healthcare access (Das \& Horton, 2013). But so far, the overall public healthcare facilities are not standard to the public demand. Since most of the public hospitals 
lack medical documentation system and modern diagnostic facilities, continuous surveillance for dengue disease is a vast challenge here (Organization, 2015). In 1964, dengue was first reported in Dhaka, hence named after as "Dacca Fever" (Aziz et al., 1967). The fever remained epidemic since then (Ahmed et al., 2001).

Dhaka had been experiencing a large-scale dengue outbreak in every year since 2000 (Akram, 2019). The dengue epidemic in 2019 at Dhaka city created serious public health problem, causing significant absence in working place. Fig 1 shows how dengue emerged on a sudden large scale. The disease caused a huge economic and social burden in the city. In this paper, the socio-economic impact was measured through the number of absent days in working place of the affected people and percentage of monthly family income spend to monthly family expenditure for occurring dengue disease. The significant covariates for occurring this disease were identified and various suggestions for knocking the disease off had been analyzed, discussed and concluding remarks made.

\section{MATERIALS AND METHODS:}

Primary data were collected from October 9 to November 20, 2019. For this purpose, a questionnaire was designed and data were collected by direct interview (face-to-face) method. Respondents were conveniently selected from Dhaka city where dengue outbreak had occurred. The study covered 235 dengue affected and 235 unaffected respondents.

The questionnaire involved seven major sections: personal (demographic) information of the respondent's, economic condition, environmental condition, disease incidence, preventive measure, treatment, and suggestions. The variables that were highlighted in this study are: family cost [Percentage of monthly income spent on expenditure], incidence [no, yes], living status [alone, with family, with friends/colleague, others], family size, marital status [single, married, divorced, widowed, separated], economic status [lower class, lower middle, middle, higher middle, higher], absence [number of days absent from work], age [0-15, 15-30, 30-45, 45-60, 60+], gender [male, female, others], treatment cost, education status [illiterate, primary, secondary, higher secondary, graduate], drainage system [bad, medium, good], providing spray by city corporation [no, yes], and area [university area, residential area, slum, crowded area, VIP area, commercial area, industrial area, hostel area, others].

Regression analysis is an important statistical method to investigate the relationships that exist between a dependent variable and a set of independent variables (Draper \& Smith, 1998; Zeileis \& Hothorn, 2002). This widely used analysis examines which factors matter most, which factors can be neglected, and how these factors influence each other (Fahrmeir et al., 2013; Montgomery et al., 2012). Regression techniques for making predictions is drive by three techniques mostly: type of dependent variables, number of independent variables, and shape of the regression line (Seber \& Lee, 2012). However, two widely used regression model, multiple linear regression and binary logistic regression, had been considered here. If independent variable is more than one and dependent variable is continuous type having linear relationship with independent variables and follows some other specific assumptions then multiple linear regression model can assess the impact of independent variables on dependent variable (Nathans et al., 2012). For the vector of covariates $\boldsymbol{x}$ and vector of response variable $\boldsymbol{Y}$, the form of the multiple linear regression model in matrix notation becomes (Brown, 2009)

$$
Y=x^{\prime} \beta+\epsilon,
$$

Where, $\boldsymbol{\beta}$ and $\boldsymbol{\epsilon}$ be the vector of regression coefficient and random error term, respectively. If the response vector $\boldsymbol{Y}$ be of binary type, that is, referring to whether an event of interest has occurred or not, binary logistic regression is used for modeling purpose, which has the following functional form (Sarkar \& Midi, 2010).

$$
\pi(\boldsymbol{x})=\frac{e^{x^{\prime} \boldsymbol{\beta}}}{1+e^{x^{\prime} \boldsymbol{\beta}}}
$$

Where, $\pi(\boldsymbol{x})$ represents the conditional mean of $\boldsymbol{Y}$ given $\boldsymbol{x}$ i.e., $E(\boldsymbol{Y} \mid \boldsymbol{x})$. In both models, the unknown parameters $(\boldsymbol{\beta})$ are estimated by the method of maximum likelihood estimation (Albert \& Anderson, 1984; Myung, 2003). Here, the former model applied for relating family cost and productivity to dengue incidence, while the factors for occurring dengue disease 
was identified by the later model. Also, multiple response analysis had been incorporated to assess various suggestions from patients.

\section{Model 1}

The impact of dengue infection on the monthly expenditure of the patient was determined by the first model (multiple linear regression models). In this model, dependent variable family cost [percentage of monthly income spent on expenditure] was used as a proxy for measuring monthly expenditure of the patient. The main independent variable was dengue incidence and related covariates were also considered. The model had the form as -

$$
\begin{aligned}
\text { family cost }_{i}= & \beta_{0}+\beta_{1} \text { incidence }_{i} \\
& +\beta_{2} \text { living status }_{i} \\
& +\beta_{3} \text { family size }_{i} \\
& +\beta_{4} \text { marital status }_{i} \\
& +\beta_{5} \text { economic status }_{i}+\epsilon_{i}, \\
& i=1,2, \cdots, n
\end{aligned}
$$

Where, $\beta$ denotes regression coefficient of the covariates and $\epsilon_{i}$ is the random error term of the $i^{\text {th }}$ respondent.

\section{Model 2}

The second model was also a multiple linear regression model which determined impact of dengue infection on human productivity. The dependent variable absence [number of days absent from work] was used as a proxy for measuring productivity of the patient. The main independent variable was dengue incidence with other related covariates. The model took the form as -

$$
\begin{aligned}
\text { absence }_{i}=\beta_{0} & +\beta_{1} \text { incidence }_{i}+\beta_{2} \text { living status }_{i} \\
& +\beta_{3} \text { family size }_{i} \\
& +\beta_{4} \text { marital status }_{i}+\beta_{5} \text { age }_{i} \\
& +\beta_{6} \text { gender }_{i}+\beta_{7} \text { treatment cost }_{i} \\
& +\epsilon_{i}, \quad i=1,2, \cdots, n
\end{aligned}
$$

Where, $\beta$ and $\epsilon_{i}$ bear the same meaning as before.

\section{Model 3}

Binary logistic regression applied for detecting risk factors of dengue disease. The acting dependent variable dengue incidence [whether dengue disease occurred or not], which was of binary type. This variable and related independent variables took the functional form as -

$$
\begin{aligned}
\text { incidence }_{i}= & \beta_{0}+\beta_{1} \text { gender }_{i}+\beta_{2} \text { age }_{i} \\
& +\beta_{3} \text { marital status }_{i} \\
& +\beta_{4} \text { education status }_{i} \\
& +\beta_{5} \text { living status }_{i} \\
& +\beta_{6} \text { drainage system }_{i} \\
& +\beta_{7} \text { providing spray }_{i}+\beta_{8} \text { area }_{i} \\
& +\beta_{9}+\epsilon_{i}, \quad i=1,2, \cdots, n ;
\end{aligned}
$$

Where, $\beta$ and $\epsilon_{i}$ bear the same meaning as before.

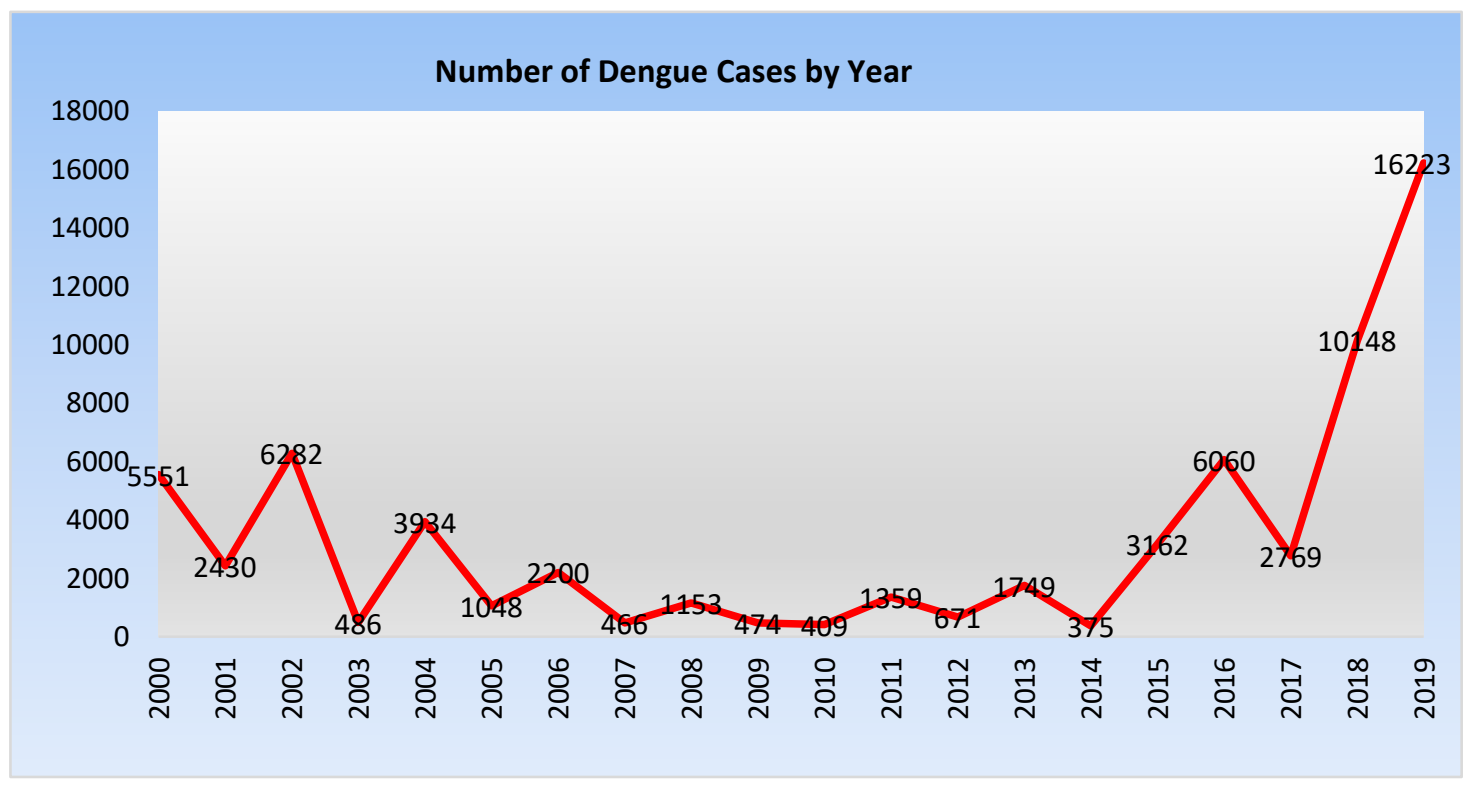

Fig 1: Year wise dengue cases in Dhaka (Data Source: Akram, 2019). 


\section{RESULTS AND DISCUSSIONS:}

The Fig 1 is a clear indication of sudden increase of dengue affected people in Dhaka in 2019. Dengue patients increased from 2769 in 2017 to 10148 in 2018, then reached the highest record 16223 in 2019. This study attempted to explore the reasons behind and the impact made in socioeconomic life in Dhaka.

Multiple linear regression and binary logistic regression models had been employed to analyze dengue patients' data. The obtained results were shown in Table 1, Table 2, and Table 3. Table 1 presented the factors related to family cost.

Table 1: Multiple linear regression model estimates of the selected covariates for family cost in Dhaka city along with standard error (SE) and p-value.

\begin{tabular}{|l|l|l|l|}
\hline Covariates & Coefficient & SE & p-value \\
\hline Constant & 69.135 & 4.699 & $<0.001$ \\
\hline Incidence & & & \\
\hline no & - & - & - \\
\hline yes & 1.498 & 1.686 & 0.375 \\
\hline Living status & & & \\
\hline alone & - & - & - \\
\hline with family & 1.925 & 2.255 & 0.394 \\
\hline others & -10.565 & 4.892 & 0.031 \\
\hline family size & 2.363 & 0.479 & $<0.001$ \\
\hline Marital status & & & \\
\hline single & - & - & - \\
\hline married & 4.210 & 2.063 & 0.042 \\
\hline divorced & -13.144 & 5.972 & 0.028 \\
\hline widowed & 7.112 & 5.187 & 0.171 \\
\hline Economic status & & & \\
\hline lower class & - & - & - \\
\hline lower middle & -12.615 & 4.150 & 0.003 \\
\hline middle & -8.102 & 3.710 & 0.029 \\
\hline higher middle & -7.214 & 4.059 & 0.076 \\
\hline higher & -15.753 & 5.437 & 0.004 \\
\hline
\end{tabular}

The obtained significant variables were living status, family size, marital status and economic status, while incidence was the only covariate that turned out as insignificant at 5\% level of significance. Living "with others" decreased the percentage of monthly income spent on expenditure by 10.565 percent compared to living "alone" keeping all other covariates constant. Living with family has no significant effect compared UniversePG I www.universepg.com to living alone at 5\% significance. Extra one person increasing in number of family member increased the percentage of monthly income spent on expenditure by 2.363 percent. Percentage of monthly income spent on expenditure increased by 4.210 percent and decreased by 13.144 percent in the married and divorced patient groups, respectively, compared to the alone patient group keeping all other independent variables fixed. The lower middle, middle, higher middle, and higher economic class patients had 12.615, 8.102, 7.214, and 15.753 percent less monthly income spent on expenditure than lower economic class patients, respectively. From Table 2, it is noticed that the covariates incidence, living status, and treatment cost were significantly affecting productivity, while family size, age, marital status and gender turned out as insignificant at $5 \%$ level of significance.

Table 2: Multiple linear regression model estimates of the selected covariates for productivity in Dhaka city along with standard error (SE) and p-value.

\begin{tabular}{|l|l|l|l|}
\hline Covariates & Coefficient & SE & p-value \\
\hline constant & 2.012 & 1.731 & 0.246 \\
\hline Incidence & & & \\
\hline no & - & - & - \\
\hline yes & 6.144 & 0.687 & $<0.001$ \\
\hline Living status & & & \\
\hline alone & - & - & - \\
\hline with family & -1.261 & 0.757 & 0.096 \\
\hline others & -1.888 & 1.590 & 0.236 \\
\hline family size & 0.085 & 0.161 & 0.599 \\
\hline Marital status & & & \\
\hline single & - & - & - \\
\hline married & -0.706 & 0.867 & 0.415 \\
\hline divorced & -2.124 & 1.991 & 0.287 \\
\hline widowed & -0.866 & 1.912 & 0.651 \\
\hline Age & & & \\
\hline $0-15$ & - & - & - \\
\hline $15-30$ & 0.629 & 1.312 & 0.632 \\
\hline $30-45$ & 0.691 & 1.450 & 0.634 \\
\hline $45-60$ & 1.937 & 1.652 & 0.242 \\
\hline $60+$ & 0.854 & 2.209 & 0.699 \\
\hline Gender & & & \\
\hline male & - & - & - \\
\hline female & 0.638 & 0.585 & 0.276 \\
\hline treatment cost & $<0.001$ & $<.001$ & $<.001$ \\
\hline & & & \\
\hline
\end{tabular}


Dengue incidence had significant effect on productivity of the patients with p-value less than 0.001 . It hampered approximately 6 working days, keeping all other covariates fixed. Living status was significant at $10 \%$ significance level. Patients living with family remained 1.261 days less absent from workplace than patients living alone, keeping all other covariates constant. The positive value of the coefficient under treatment cost denoted more absence in workplace with the higher treatment cost. That is, the more a patient had to pay for dengue, the more he remained absent in workings (Shazeed-Ul-Karim, 2019).

The risk factors that are acting behind to occur dengue fever were shown in Table 3. The variables living status, drainage system, providing spray, and area were found significant in Table 3 while gender, age, marital status, and education status were insignificant.

Table 3: Binary logistic regression model estimates of the selected covariates for dengue incidence in Dhaka along with standard error (SE), hazard ratio (HR), and p-value.

\begin{tabular}{|c|l|l|l|l|}
\hline Covariates & Coefficient & SE & HR & p-value \\
\hline constant & 0.541 & 1.207 & 1.717 & 0.654 \\
\hline Gender & & & & \\
\hline male & - & - & - & - \\
\hline female & 0.077 & 0.227 & 1.080 & 0.733 \\
\hline Age & & & & \\
\hline $0-15$ & - & - & - & - \\
\hline $15-30$ & 0.748 & 0.985 & 2.112 & 0.448 \\
\hline $30-45$ & 0.211 & 0.853 & 1.235 & 0.804 \\
\hline $45-60$ & 0.405 & 0.826 & 1.499 & 0.624 \\
\hline $60+$ & -0.252 & 0.846 & 0.777 & 0.766 \\
\hline Marital status & & & & \\
\hline single & - & - & - & - \\
\hline married & -0.517 & 0.341 & 0.596 & 0.779 \\
\hline widowed & -3.231 & 1.263 & 0.040 & 0.211 \\
\hline Education status & & & & \\
\hline Illiterate & - & - & - & - \\
\hline primary & 0.442 & 0.806 & 1.556 & 0.583 \\
\hline secondary & 0.403 & 0.618 & 1.497 & 0.514 \\
\hline higher & -0.375 & 0.488 & 0.688 & 0.442 \\
\hline graduate & 0.232 & 0.419 & 1.262 & 0.579 \\
\hline Living status & & & & \\
\hline alone & - & - & - & - \\
\hline with family & -2.048 & 1.135 & 0.129 & 0.071 \\
\hline
\end{tabular}

UniversePG I www.universepg.com

\begin{tabular}{|c|l|l|l|l|}
\hline with friends & -0.954 & 0.712 & 0.181 & 0.385 \\
\hline others & -0.646 & 0.690 & 0.349 & 0.524 \\
\hline Drainage & & & & \\
\hline bad & - & - & - & - \\
\hline medium & 0.469 & 0.389 & 1.598 & 0.228 \\
\hline good & -2.116 & 0.677 & 0.121 & 0.002 \\
\hline Providing & & & & \\
\hline no & - & - & - & - \\
\hline yes & -0.780 & 0.239 & 0.459 & 0.001 \\
\hline Area & & & & \\
\hline university & - & - & - & - \\
\hline residential & -1.653 & 0.611 & 0.191 & 0.007 \\
\hline slum & 0.309 & 0.293 & 1.361 & 0.298 \\
\hline crowded & 0.291 & 0.417 & 1.337 & 0.486 \\
\hline VIP & -2.038 & 0.711 & 0.130 & 0.004 \\
\hline commercial & -1.716 & 0.702 & 0.180 & 0.014 \\
\hline industrial & -1.294 & 0.846 & 0.126 & 0.180 \\
\hline hostel & 0.458 & 0.866 & 1.581 & 0.597 \\
\hline
\end{tabular}

The respondents living with family had 2.048 times significantly less odds of occurring dengue disease at $10 \%$ significance level than respondents living alone. The respondents provided with good drainage system had experienced $87.9 \%$ fewer odds compared to bad drainage system and this is highly significant at $1 \%$ level of significance having p-value 0.002. Providing spray in the locality was significant at $1 \%$ significance level with p-value 0.001 bringing $54.1 \%$ less odds of experiencing dengue disease compared to from not providing spray. The patients belonging to residential, VIP, and commercial area had significantly 1.653 , 2.038, and 1.716 times less odds, respectively, of having this disease at $5 \%$ level of significance than patients from university area.

Table 4: Multiple response analysis of used preventive approach of the dengue affected respondents in Dhaka city.

\begin{tabular}{|l|l|}
\hline Preventive approach & Percentage (\%) \\
\hline Nothing & 5.5 \\
\hline Coil & 44.1 \\
\hline Aerosol & 35.3 \\
\hline Liquid & 17.5 \\
\hline Mosquito racket & 27.9 \\
\hline Net & 57.8 \\
\hline
\end{tabular}


Multiple Response Analysis - Multiple response analysis is an analysis of frequency when more than one response can be obtained from each participant. Multiple responses had been arranged in three portions in this study: preventive approaches of dengue, suggestions about people's steps on prevention of dengue, suggestions about government's steps on prevention of dengue.
Table 4 showed that $5.5 \%$ patients who were affected by dengue didn't use any approach such as coil, aerosol, liquid, mosquito racket, net, etc. $44.1 \%$ patients used coil, $35.3 \%$ patients used aerosol, $17.5 \%$ of patients used liquid, $27.9 \%$ patients used mosquito racket and $57.8 \%$ patients used net as a preventive approach to protect from dengue.

Table 5: Multiple response analysis of the suggestions regarding necessary steps that people might take to prevent dengue disease.

\begin{tabular}{|l|l|}
\hline Necessary steps & Percentage (\%) \\
\hline No step & 7.9 \\
\hline Cover tightly all water containers & 33.3 \\
\hline Burring unused tires keeping drain free from blockage & 37.5 \\
\hline Keep drain free from blockage & 60.8 \\
\hline Changing water regularly in plant container & 61.3 \\
\hline Changing water from trays under the fridge & 39.9 \\
\hline Destroying unused containers & 29.9 \\
\hline Use mosquito repellent and net when sleeping & 65.1 \\
\hline Other steps & 19.8 \\
\hline
\end{tabular}

It was observed from Table 5 that $7.9 \%$ people had no suggestions, $33.3 \%$ people preferred that they could cover tightly all water containers, $37.5 \%$ people had opinion that they could burry unused tiers, $60.8 \%$ people wanted to keep drain free from blockage, $61.3 \%$ people could change water in plant container, $39.9 \%$ people preferred to change water in trays under the fridge, $29.9 \%$ people could destroy/burn unused containers, $65.1 \%$ people also said that they could use mosquito repellent and mosquito net when sleeping and $19.8 \%$ of people preferred to take others steps to prevent dengue fever transmission during outbreak.

Table 6: Multiple response analysis of the suggestions regarding necessary steps that government might take to prevent dengue disease.

\begin{tabular}{|l|l|}
\hline Necessary steps & Percentage (\%) \\
\hline Repairing open manhole & 42.8 \\
\hline Developing drainage system & 65.7 \\
\hline Removing blocked water & 47.3 \\
\hline Providing regular mosquito & 69.4 \\
\hline Keeping the locality clean & 41.2 \\
\hline
\end{tabular}

From Table 6, 42.8\% people were found who thought that government could repair open manhole, $65.7 \%$ UniversePG I www.universepg.com people wanted that government could develop the drainage system, $47.3 \%$ people preferred that government should remove blocked water source, $69.4 \%$ people wanted that government should provide regular mosquito spray, and $41.2 \%$ people suggested government should keep the locality clean.

This paper primarily measured the impact of dengue both on society and economy. It was observed that dengue had no significant effect on family expenditure. The underlying reason is that the treatment of dengue was not that expensive to affect the total family cost. But, this result contradicted some previous work (Clark et al., 2005; Halasa et al., 2012; Harving \& Ronsholt, 2007). However, dengue fever badly affected the human productivity, which was similar to previous works on this disease (Bhavsar et al., 2010; Halasa et al., 2012; Serufo et al., 1993). Since dengue had no direct economic impact but as it affected productivity, it might affect the national economy indirectly. Again, living status and treatment cost had significant effect on productivity, while living status, marital status, and economic status were significant to the family cost of the respondents. 


\section{CONCLUSION AND RECOMMENDATIONS:}

A self-collected dataset was analyzed through sophisticated statistical modeling approaches to suspect socio-economic impact of dengue. The analysis found no direct effect of dengue on family cost, but it affected productivity which in terms might affect economy. The analysis revealed that alone living group are in greater risk of dengue (Kularatne, 2015). It might be the case that living alone people didn't take enough protection against mosquito bite, hence experienced the fever. People with bad drainage system experienced dengue disease, which might happen for blocked drains that grew and reserved mosquitos (Singh, 2007). The result expressed that providing mosquito spray decreased dengue incidence which comply with previous literature (Chadee, 2013). The probability of being affected varied significantly by different areas (Pathirana et al., 2009). Cleanliness of living areas is a must for preventing the disease which was proven in literature (Pai et al., 2006). From the multiple response analysis, it was observed that a few number of respondents used no preventive approach, while majority used mosquito net as preventive approach. Using mosquito net is effective, as this practice was suggested in literature (Nalongsack, Yoshida, Morita, Sosouphanh, \& Sakamoto, 2009). The respondents suggested mostly to use mosquito repellent and net, keep drain free from blockage, and regular changing water from plant container. They suggested government to provide mosquito spray and develop drainage system regularly.

Alone living people were more prone to experience the disease, which might occur due to their insincerity about this disease. So, the living alone persons need to increase their consciousness considering the seriousness of this disease. Drainage system is an important issue for a high densely populated capital like Dhaka city. Government should focus to have well developed systems for neat and clean drains in the capital. City Corporation should provide mosquito spray to a regular basis as it had significant influence to decrease dengue incidence. The magnitude of dengue was different at different areas. Respondents highly recommended using mosquito repellent and net during sleeping, changing water regularly from plant container, providing regular mosquito spray and developing drainage system in Dhaka city. People should become conscious enough about the disease remembering all of its hazards.

\section{ACKNOWLEDGMENT:}

First and foremost, the author is grateful to Almighty Allah. The author is also thankful to anonymous reviewers and editors for their helpful comments and suggestions.

\section{CONFLICTS OF INTEREST:}

The author declares no conflict of interest.

\section{REFERENCES:}

1. Ahmed, F. U., Mahmood, C. B., Sharma, J. D., Hoque, S. M., Zaman, R., \& Hasan, M. S. (2001). Dengue and Dengue Haemorrhagic Fever in Children During the 2000 Outbreak in Chittagong, Bangladesh, Dengue Bulletin, 25: 33-39.

https://apps.who.int/iris/bitstream/handle/10665/ 163693/dbv25p33.pdf

2. Akram, A. (2019). Alarming turn of dengue fever in Dhaka city in 2019. Bangladesh Journal of Infectious Diseases, 6(1), 1-2. https://doi.org/10.3329/bjid.v6i1.42627

3. Albert, A., \& Anderson, J. A. (1984). On the existence of maximum likelihood estimates in logistic regression models. Biometrika, 71(1), 1-10. https://doi.org/10.1093/biomet/71.1.1

4. Aziz, M., Gorham, J., \& Gregg, M. (1967). " Dacca fever"-an outbreak of dengue. Pakistan Journal of Medical Research, 6(2), 83-92. https://www.cabdirect.org/cabdirect/abstract/196 $\underline{82704480}$

5. Bhavsar, A. T., Shepard, D. S., Suaya, J. A., Mafowosofo, M., \& Hurley, C. L. (2010). A private hospital-based study assessing knowledge, attitudes, practices and costs associated with dengue illness in Surat, India. India Dengue Bull. 34: 54-64.

https://apps.who.int/iris/handle/10665/170975

6. Brown, S. H. (2009). Multiple linear regression analysis: a matrix approach with MATLAB. Alabama Journal of Mathematics, 34, 1-3. http://ajmonline.org/2009/brown.pdf 
7. Chadee, D. D. (2013). Resting behaviour of Aedes aegypti in Trinidad: with evidence for the re-introduction of indoor residual spraying (IRS) for dengue control. Parasites \& vectors, 6(1), 255.

https://parasitesandvectors.biomedcentral.com/ar ticles/10.1186/1756-3305-6-255

8. Clark, D. V., Mammen Jr, M. P., Nisalak, A., Puthimethee, V., \& Endy, T. P. (2005). Economic impact of dengue fever/dengue hemorrhagic fever in Thailand at the family and population levels. The American journal of tropical medicine and hygiene, 72(6), 786-791. https://pubmed.ncbi.nlm.nih.gov/15964964/

9. Das, P., \& Horton, R. (2013). Bangladesh: innovating for health. The Lancet, 9906(382), 1681-1682. https://doi.org/10.1016/S0140-6736(13)62294-1

10. Draper, N. R., \& Smith, H. (1998). Applied regression analysis ( $3^{\text {rd }}$ Edition): John Wiley $\&$ Sons.

https://doi.org/10.1002/1097-0258(20001130) 19:22\%3C3136::AID-SIM607\%3E3.0.CO;2-Q

11. Fahrmeir, L., Kneib, T., Lang, S., \& Marx, B. (2013). Regression models Regression (pp. 21-72): Springer. https://doi.org/10.1007/978-3-642-34333-9

12. Halasa, Y. A., Shepard, D. S., \& Zeng, W. (2012). Economic cost of dengue in Puerto Rico. The American journal of tropical medicine and hygiene, 86(5), 745-752.

https://doi.org/10.4269/ajtmh.2012.11-0784

13. Harving, M. L., \& Ronsholt, F. F. (2007). The economic impact of dengue hemorrhagic fever on family level in Southern Vietnam. Dan Med Bull, 54(2), 170-172.

https://pubmed.ncbi.nlm.nih.gov/17521539/

14. Kularatne, S. A. (2015). Dengue fever. Bmj, 351, h4661. https://doi.org/10.1136/bmj.h4661

15. Kumar, C. J., Baboo, C. A., Krishnan, B. U., Kumar, A., Joy, S., Jose, T., Hegde, B. M. (2007). The socioeconomic impact of the chikungunya viral epidemic in India. Open Medicine, 1(3), e150.

https://www.ncbi.nlm.nih.gov/pmc/articles/PMC $\underline{3113220 /}$
16. Mahmood, B., \& Mahmood, S. (2011). Emergence of Dengue in Bangladesh a major international public health concern in recent years. Journal of Environmental Research and Management, 2(3), 35-41.

http://www.e3journals.org/cms/articles/1330778 330_Belal\%20and\%20Shakeel.pdf

17. Montgomery, D. C., Peck, E. A., \& Vining, G. G. (2012). Introduction to linear regression analysis $\left(5^{\text {th }}\right.$ Edition): John Wiley \& Sons.

18. Myung, I. J. (2003). Tutorial on maximum likelihood estimation. Journal of mathematical Psychology, 47(1), 90-100. https://doi.org/10.1016/S0022-2496(02)00028-7

19. Naish, S., Dale, P., Mackenzie, J. S., McBride, J., Mengersen, K., \& Tong, S. (2014). Climate change and dengue: a critical and systematic review of quantitative modelling approaches. BMC infectious diseases, 14(1), 167.

https://doi.org/10.1186/1471-2334-14-167

20. Nalongsack, S., Yoshida, Y., Morita, S., Sosouphanh, K., \& Sakamoto, J. (2009). Knowledge, attitude and practice regarding dengue among people in Pakse, Laos. Nagoya J Med Sci, 71(1-2), 29-37.

https://pubmed.ncbi.nlm.nih.gov/19358473/

21. Nathans, L. L., Oswald, F. L., \& Nimon, K. (2012). Interpreting multiple linear regression: A guidebook of variable importance. Practical Assessment, Research, and Evaluation, 17(1), 9. https://doi.org/10.7275/5FEX-B874

22. Okanurak, K., Sommani, S., \& Indaratna, K. (1997). The cost of dengue hemorrhagic fever in Thailand. Southeast Asian Journal of Tropical Medicine and Public Health, 28, 711717. https://pubmed.ncbi.nlm.nih.gov/9656390/

23. Organization, W. H. (2015). Bangladesh health system review: Manila: WHO Regional Office for the Western Pacific. https://apps.who.int/iris/handle/10665/208214

24. Pai, H.-H., Hong, Y.-J., \& Hsu, E.-L. (2006). Impact of a short-term community-based cleanliness campaign on the sources of dengue vectors: an entomological and human behavior study. Journal of environmental health, 68(6). https://pubmed.ncbi.nlm.nih.gov/16483083/ 
25. Pathirana, S., Kawabata, M., \& Goonatilake, R. (2009). Study of potential risk of dengue disease outbreak in Sri Lanka using GIS and statistical modelling. Journal of Rural and Tropical Public Health, 8, 8 .

https://scu.esploro.exlibrisgroup.com/discovery/f ulldisplay/alma991012820691602368/61SCU_I

NST:ResearchRepository?tags=scholar

26. Sarkar, S., \& Midi, H. (2010). Importance of assessing the model adequacy of binary logistic regression. Journal of Applied Sciences, 10(6), 479-486.

https://doi.org/10.3923/jas.2010.479.486

27. Seber, G. A., \& Lee, A. J. (2012). Linear regression analysis (Vol. 329): John Wiley \& Sons.

https://www.academia.edu/32085934/Linear_Re gression Analyisis 2nd edition George A F S S eber_Alan_J_Lee_pdf

28. Serufo, J. C., Souza, A. M., Tavares, V. A., Jammal, M. C., \& Silva, J. G. (1993). Dengue in the south-eastern region of Brazil: historical analysis and epidemiology. Revista de saúde pública, 27, 157-167. https://doi.org/10.1590/s0034-891019930003 $\underline{00002}$

29. Shazeed-Ul-Karim, (2019). Dengue and recent mosquito-borne viral fever outbreak in Bangladesh: concern, causes and control, Am. J. Pure Appl. Sci., 1(6), 44-48. https://doi.org/10.34104/ajpab.019.01944048

30. Sharmin, S., Viennet, E., Glass, K., \& Harley, D. (2015). The emergence of dengue in Bangladesh: epidemiology, challenges and future disease risk. Transactions of The Royal Society of Tropical Medicine and Hygiene, 109(10), 619-627.

https://doi.org/10.1093/trstmh/trv067

31. Singh, B. (2007). Dengue outbreak in 2006: Failure of public health system? Indian Journal of Community Medicine, 32(2), 99. https://doi.org/10.4103/0970-0218.35643

32. Zeileis, A., \& Hothorn, T. (2002). Diagnostic checking in regression relationships. https://cran.r-project.org/web/packages/lmtest/ vignettes/lmtest-intro.pdf

Citation: Uddin MA. (2020). Exploring socio-economic impact of dengue fever in Dhaka city: a statistical modeling approach, Eur. J. Med. Health Sci., 2(6), 125-133. https://doi.org/10.34104/ejmhs.020.01250133 (c) 